TEMAS EMERGENTES

\title{
La prisión preventiva oficiosa atenta contra la democracia y favorece a la dictadura
}

\author{
Automatically pretrial detention undermines democracy \\ and favours dictatorship
}

\author{
Antonio Salcedo Flores (iD \\ Universidad Autónoma Metropolitana, México
}

\begin{abstract}
RESUMEN Este trabajo expone y analiza la prisión preventiva oficiosa a la luz de diversos ordenamientos jurídicos y jurisprudencia en materia de derechos humanos. Muestra cómo es manipulada para restringir derechos fundamentales, perpetuarse en el ejercicio del poder, impedir la celebración de elecciones periódicas, libres, justas y basadas en el sufragio como expresión de la soberanía del pueblo; para impedir la existencia y la organización de los opositores políticos; para despojar a la judicatura no solo de su independencia, sino de toda su jurisdicción. Ello por medio de flagrantes violaciones a las leyes nacionales, a las convenciones internacionales, a las recomendaciones e instancias de los organismos internacionales. La investigación fue realizada en México, no obstante, los problemas identificados pueden extenderse a cualquier país de América Latina, particularmente a Chile, Argentina, Uruguay y a Venezuela, en virtud de que la prisión preventiva oficiosa, también llamada arbitraria, es un ataque frontal contra la democracia que favorece la instauración, el regreso y el fortalecimiento de la dictadura.
\end{abstract}

PALABRAS CLAVE Libertad, presunción de inocencia, garantías judiciales, derechos humanos, Corte Interamericana de Derechos Humanos.

ABSTRACT This work exposes and analyzes automatically pretrial detention, in the light of domestic legal system and international jurisprudence on human rights. It shows how it is manipulated to restrict fundamental rights, perpetuate the exercise of power, prevent the holding of periodic, free and fair elections based on suffrage as an expression of the sovereignty of the people, to prevent the existence and organization of political opponents, and also to strip the judiciary not only of its independence, but of all its jurisdiction. The above through flagrant violations of domestic legal system, international conventions and recommendations of international mechanisms from universal and regional systems. This research was carried out in Mexico, however, the identified problems may extend to any country in Latin America, particularly Chile, 
Argentina, Uruguay and Venezuela, inasmuch as the automatically pretrial detention, also called arbitrary, is a frontal attack against democracy, that favors the establishment, return and/or strengthening of the dictatorship.

KEYWORDS Liberty, presumption of innocence, judicial guarantees, human rights, Inter-American Court of Human Rights.

\section{Introducción}

La prisión preventiva oficiosa, también llamada automática, obligatoria, forzosa y arbitraria, es el encarcelamiento de una persona por el solo hecho de ser señalada por las fuerzas de seguridad como partícipe en la ejecución de un hecho que el grupo en el poder ha enlistado como «delito grave». A diferencia de la prisión preventiva justificada, ${ }^{1}$ la prisión preventiva oficiosa excluye al juez en la decisión de su aplicación. El encierro lo decreta el Poder Legislativo antes de que ocurran los hechos, sin considerar prueba alguna y sin competencia para hacerlo. Entonces, la persona señalada se ve privada de sus derechos humanos de libertad personal, presunción de inocencia, debido proceso y de acceso a la justicia. Prácticamente ha sido condenada. En México, casi el 95\% de los casos en que los jueces del fuero común imponen la prisión preventiva justificada termina resolviéndose con sentencia condenatoria. ${ }^{2} \mathrm{La}$ situación empeora con la prisión preventiva oficiosa, medida que el juez está obligado a imponer, sin que pueda eludirla o siquiera justificarla en motivación alguna; debe ordenarla porque la conducta que le han consignado se encuentra enlistada o autorizada por el artículo 19 constitucional:

El juez ordenará la prisión preventiva oficiosamente en los casos de abuso o violencia sexual contra menores, delincuencia organizada, homicidio doloso, feminicidio, violación, secuestro, trata de personas, robo de casa habitación, uso de programas sociales con fines electorales, corrupción tratándose de los delitos de enriquecimiento ilícito y ejercicio abusivo de funciones, robo al transporte de carga en cualquiera de sus modalidades, delitos en materia de hidrocarburos, petrolíferos o petroquími-

1. Para mayor información sobre la naturaleza de la prisión preventiva en lo general y de la prisión preventiva justificada, que son dos medidas menos drásticas que la prisión preventiva oficiosa, puede verse Salcedo (2018a).

2. «Estudios sobre la población carcelaria en México 2010», Cámara de Diputados, Centro de Estudios Sociales y de Opinión Pública, en coordinación con el Centro de Investigación y Docencia Económicas. Aún no contamos con datos precisos sobre cuántas personas han sido condenadas después de que se les haya impuesto la prisión preventiva oficiosa, medida que terminó de implementarse en nuestro país en 2016; no obstante, estimamos que el porcentaje debe ser superior al de la prisión preventiva justificada, en atención a que la medida oficiosa es más aprehensiva. 
cos, delitos en materia de desaparición forzada de personas y desaparición cometida por particulares, delitos cometidos con medios violentos como armas y explosivos, delitos en materia de armas de fuego y explosivos de uso exclusivo del Ejército, la Armada y la Fuerza Aérea, así como delitos graves que determine la ley en contra de la seguridad de la nación, el libre desarrollo de la personalidad y de la salud.

La lista es permanente y tendenciosamente manipulada por medio de leyes secundarias - constitucionales e inconstitucionales-, según lo requieran los intereses políticos del momento y siempre en detrimento de la democracia, de la Constitución mexicana, de la Declaración Universal de los Derechos Humanos, de la Convención Americana sobre Derechos Humanos y del Pacto Internacional de Derechos Civiles y Políticos.

El Poder Constituyente mexicano y los legisladores secundarios, al mes de septiembre de 2021, han integrado una lista de 77 delitos sancionados con prisión preventiva oficiosa. Esto resulta preocupante si tomamos en cuenta que, cuando la medida cautelar apareció en 2008, se dispuso para cinco delitos graves; en 2011 se les sumó el delito de trata de personas; en 2019 se agregaron ocho delitos, en su mayoría patrimoniales privados y públicos; y en febrero de 2021, la lista se aumentó con 63 delitos más, entre los que se encuentran delitos no graves, delitos relacionados con el derecho al voto, la consulta popular y la protesta social; lo que quiere decir que esta clase de privación preventiva de la libertad, aumenta vertiginosamente, tanto en cantidad como en invasión de aspectos democráticos esenciales.

Ante tan sombrío panorama, varios organismos internacionales de derechos humanos, entre los que se encuentran el Grupo de Trabajo sobre Detención Arbitraria, el Comité contra la Tortura, la Oficina en México del Alto Comisionado para los Derechos Humanos - todos ellos de la Organización de las Naciones Unidas- y la Comisión Interamericana de Derechos Humanos, se han dirigido en numerosas ocasiones al Estado mexicano, recomendándole e instándole a que derogue de su sistema jurídico nacional la prisión preventiva oficiosa o, cuando menos, la adecúe a los estándares que el mismo gobierno ha establecido al firmar, ratificar y convalidar los tratados internacionales que hemos mencionado.

El Grupo sobre Detención Arbitraria ha ido más lejos. En varias de sus opiniones ha advertido al Estado mexicano que la prisión preventiva oficiosa atenta contra la autonomía y la independencia de los jueces, auspicia la tortura y otros tratos o penas crueles, inhumanos o degradantes, y podría constituir crímenes de lesa humanidad, ${ }^{3}$ razones por las que, además, y en forma reiterada, ha venido dando intervención al Relator Especial de la Organización de las Naciones Unidas sobre independencia

3. Sobre el carácter de crimen de lesa humanidad de la prisión preventiva oficiosa, puede verse Salcedo (2019). 
de los magistrados y abogados, así como al Relator Especial de la Organización de las Naciones Unidas sobre la tortura y otros tratos o penas crueles, inhumanos o degradantes. ${ }^{4}$

¿Por qué tanta preocupación de los organismos internacionales de derechos humanos? ¡Veámoslo!

\section{Antijuridicidad de la prisión preventiva oficiosa}

La Declaración Universal de los Derechos Humanos, manda en el artículo 10: «Toda persona tiene derecho a ser oída por un tribunal independiente e imparcial para el examen de cualquier acusación contra ella en materia penal». En el diverso 11.1, ordena: «Toda persona acusada de delito tiene derecho a que se presuma su inocencia mientras no se pruebe su culpabilidad conforme a la ley y en juicio público en el que se hayan asegurado todas las garantías necesarias para su defensa».

La Convención Americana sobre Derechos Humanos, en el artículo 8.1, dispone: «Toda persona tiene derecho a ser oída, con las debidas garantías y dentro de un plazo razonable, por un juez o tribunal competente, independiente e imparcial, establecido con anterioridad por la ley, en la sustanciación de cualquier acusación penal formulada contra ella». En el artículo 8.2, determina: «Toda persona inculpada de delito tiene derecho a que se presuma su inocencia mientras no se establezca legalmente su culpabilidad».5

Por su parte, el Pacto Internacional de Derechos Civiles y Políticos, en el artículo 14.1, preceptúa: «Toda persona tendrá derecho a ser oída públicamente y con las debidas garantías por un tribunal competente, independiente e imparcial, establecido por la ley, en la substanciación de cualquier acusación de carácter penal formulada contra ella». En el diverso 14.2, establece: «Toda persona acusada de un delito tiene derecho a que se presuma su inocencia mientras no se pruebe su culpabilidad conforme a la ley».

Como podemos ver, todos y cada uno de los ordenamientos normativos invocados prescriben:

4. Cfr. Grupo de Trabajo sobre Detención Arbitraria de Naciones Unidas, Opinión 1/2018, párrs. 73 y 82; Opinión 14/2019, párrs. 84 y 92; y Opinión 64/2019, párrs. 97 y 105.

5. Este punto lo expone ampliamente Juana María Ibáñez Rivas en el Comentario de la Convención Americana sobre Derechos Humanos, editado en 2019 por Konrad Adenahuer Stiftung, pp. 256-322. Ahí mismo, Jesús María Casal Hernández, sintetiza el por qué la prisión preventiva de una persona solo puede y debe ser decretada por un juez: «La obligación de llevar a la persona detenida ante una autoridad judicial, permite al juez tomar control sobre la observancia de las garantías de la privación de libertad» (página 244). 
- La única autoridad competente para conocer y resolver cualquier acusación penal es el juez. ${ }^{6}$

- Toda persona acusada de un delito goza de la presunción de inocencia. ${ }^{7}$

En México, el juez no puede ordenar la prisión preventiva contra las personas acusadas por uno de los delitos que aparecen en la lista del artículo 19 constitucional o en las listas de las leyes secundarias; él solo debe acatarla, ya que así se lo impone la letra del artículo 19: «El juez ordenará la prisión preventiva, oficiosamente, en los casos de [...]». Tenemos, entonces, que quien en realidad decreta la prisión preventiva en esos casos es el legislador, quien la decreta sin conocer los hechos, sin apreciar las pruebas y sin competencia jurisdiccional. Lo hace violando flagrantemente el derecho de la persona acusada a que sea un juez, y solo un juez, quien conozca y resuelva la acusación que la señala como partícipe en la comisión de uno de los delitos enlistados para prisión preventiva obligatoria, lo hace ignorando su derecho a la presunción de inocencia. Derechos fundamentales: a un juez y a la presunción de inocencia, que, como vimos, se encuentran protegidos por normas fundamentales del derecho internacional.

De lo anterior se sigue que la prisión preventiva oficiosa, por ser una encarcelación regulada desde la Constitución y las leyes secundarias, es sistemática; por tener como destinatarias a todas las personas que sean señaladas como partícipes de los delitos enlistados en la Constitución y en las leyes secundarias, es generalizada; $y$, por atentar en contra del derecho a que sea un juez quien resuelva la acusación penal presentada contra la persona señalada, así como en contra de su presunción de inocencia, viola la Declaración Universal de los Derechos Humanos, la Convención Americana sobre Derechos Humanos y el Pacto Internacional de Derechos Civiles y Políticos, que son normas fundamentales de derecho internacional. Por lo tanto, la prisión preventiva oficiosa es un crimen de lesa humanidad (salcedo, 2019), según el Estatuto de Roma de la Corte Penal Internacional, artículo 7, párrafo 1, inciso e):

A los efectos del presente Estatuto, se entenderá por crimen de lesa humanidad cualquiera de los actos siguientes cuando se cometa como parte de un ataque generalizado o sistemático contra una población civil y con conocimiento de dicho

6. «El artículo 7.6 de la Convención es claro al disponer que la autoridad que debe decidir la legalidad del arresto o detención debe ser "un juez o tribunal". Con ello la Convención está resguardando que el control de la privación de la libertad debe ser judicial». Sentencia del caso Vélez Loor con Panamá, Corte Interamericana de Derechos Humanos, serie C núm. 218, excepciones preliminares, fondo, reparaciones y costas, 23 de noviembre de 2010, párr. 126.

7. Sobre este punto, puede consultarse a Llobet Rodríguez (2009). Allí mismo se expone el principio de proporcionalidad entre la falta y la medida cautelar, en su carácter de sanción negativa. 
ataque [...] e) Encarcelación u otra privación grave de la libertad física en violación de normas fundamentales de derecho internacional.

He ahí el porqué de la preocupación en los organismos internacionales.

\section{La actitud del Estado mexicano}

El gobierno mexicano, hasta el día de hoy, ha ignorado las recomendaciones y las instancias (apremios, llamamientos) de los organismos internacionales y, en sentido contrario a ellas, ha aumentado y sigue aumentando la lista de los delitos a los que les impone la prisión preventiva oficiosa. A partir de abril de 2019, viene ampliando de manera alarmante la lista con hechos que benefician más al grupo en el poder que a la sociedad. Por ejemplo, incluyó entre los delitos que merecen prisión preventiva automática a la evasión de impuestos y al contrabando, así como a los delitos en materia de hidrocarburos, petrolíferos o petroquímicos, ilícitos cuya perpetración merma directamente los ingresos materiales del Estado. También puso en la lista dos delitos electorales: i) las amenazas de suspender los beneficios de programas sociales cuando se relacionen con fines electorales, a pesar de que este delito no es grave ni contra la seguridad nacional, el libre desarrollo de la personalidad o la salud; y ii) cualquier presión que se ejerza en el electorado que participe o no participe en el procedimiento de la consulta popular, así persigue al derecho a la información, a la expresión, a la conciencia, a la crítica. No olvidó el derecho a la protesta: a él le aumentó la penalidad para hacerlo delito grave y lo incluyó en la lista.

En febrero de 2021, el Congreso de la Unión —que en México es el legislador jerárquicamente superior- llevó a cabo una reforma de amplio calado sobre la prisión preventiva oficiosa, a fin de «armonizar» - dijeron los legisladores- nueve leyes federales con la lista del artículo 19 constitucional, así como para sumar conductas que, aunque no están en dicha lista, pueden agregarse por la autorización que a los legisladores secundarios concede el precepto constitucional. Lo peor del caso es que también incluyó conductas no autorizadas por el artículo 19, y, por lo tanto, doblemente prohibidas, con el objetivo de perpetuar ilegítimamente en el poder al actual grupo gobernante. Una de esas conductas doblemente prohibidas la estableció en los artículos 6 y 7 de la Ley General en Materia de Delitos Electorales (LGMDE): «La persona juzgadora ordenará la prisión preventiva oficiosa tratándose de los delitos previstos en los artículos 7, fracción VII, párrafo tercero»:

Se impondrán de cincuenta a cien días multa y prisión de seis meses a tres años, a quien: [...] 7. Amenace con suspender los beneficios de programas sociales, ya sea por no participar en eventos proselitistas, o bien, para la emisión del sufragio en favor de un candidato, partido político o coalición; o a la abstención del ejercicio del derecho de voto o al compromiso de no votar a favor de un candidato, partido político o coalición. 
Con la persecución del derecho al voto, el actual gobierno mexicano, en franca violación de su mandato y del artículo 19 de la Constitución, que a su vez viola las convenciones internacionales antes mencionadas, ${ }^{8}$ aumentó la lista de los delitos que merecen prisión preventiva oficiosa para, con este encarcelamiento general y sistemático, deshacerse de sus opositores políticos, vengarse de sus enemigos del pasado y el presente, e impedir que la sociedad se organice, vote y elija libremente a sus representantes.

El artículo 19 constitucional no contempla entre los delitos que merecen prisión preventiva oficiosa a las amenazas de suspender los beneficios de programas sociales, en relación con fines electorales; sin embargo, por medio de una ley secundaria, dichas amenazas fueron sumadas a la lista, ya que resultan muy provechosas para conservar a los «clientes» electorales, para acallar a la crítica, amagar a la oposición, implantar los regímenes absolutistas, autoritarios y dictatoriales, así como para dirigir a los electores en el rumbo «correcto».

La consulta popular no se salvó, fue incorporada a la lista de los delitos que merecen prisión preventiva oficiosa. Esta se aplicará «a quien, utilizando bienes, fondos, servicios o beneficios relacionados con programas sociales, ejerza cualquier tipo de presión sobre el electorado [...] para votar o abstenerse de votar por alguna opción durante el procedimiento de consulta popular».

Como puede verse, en el término «cualquier tipo de presión», caben muchas cosas, incluidos el análisis, la conciencia, la información, la discusión, la crítica, la organización, la protesta.

El derecho a protestar también fue capturado. De delito leve lo convirtieron en grave, de conformidad con el artículo 150, fracción 1, del Código Nacional de Procedimientos Penales. Lo sancionaron con prisión preventiva forzosa, que es otro nombre para la prisión preventiva oficiosa. A la protesta la reprimen con el artículo $533 \mathrm{de}$ la Ley de Vías Generales de Comunicación:

A quien dañe, perjudique o destruya las vías generales de comunicación, o los medios de transporte, o interrumpa la construcción de dichas vías, o total o parcialmente interrumpa o deteriore los servicios que operen en las vías generales de comunicación o los medios de transporte, se le sancionará con pena de dos a nueve años y multa de doscientas a mil veces el valor diario de la Unidad de Medida y Actualización al momento de cometerse el delito.

La construcción de vías generales de comunicación siempre afecta predios particulares, ejidales, comunales, tribales, de pueblos originarios; si contra la afectación alguien protesta y con su protesta interrumpe la construcción de vías generales de comunicación, el inconforme será detenido y sujeto a prisión preventiva automática,

8. Sobre este tema, puede verse Salcedo (2018b). 
cuyos efectos, dice la ley, pueden durar hasta dos años, por lo que, sin importar que la persona detenida resulte absuelta o condenada, cuando salga de prisión, la vía general de comunicación ya estará concluida y su derecho a protestar se habrá perdido irremediablemente.

\section{La prisión preventiva oficiosa y las consultas populares}

El actual presidente de México - quien fue derrotado en las elecciones para dicho cargo por Felipe de Jesús Calderón Hinojosa en 2006, y por Enrique Peña Nieto en 2012- pidió y presionó a la Suprema Corte de Justicia de la Nación, a través de diversos instrumentos, entre los que no podían faltar los medios masivos de comunicación, a fin de que declarara constitucional una consulta popular para investigar, y en su caso sancionar, a cinco expresidentes de México, entre quienes se encuentran, claro está, los dos que en su oportunidad lo derrotaron. Propuso que la consulta popular se realizara con la pregunta:

¿Está de acuerdo o no con que las autoridades competentes, con apego a las leyes y procedimientos aplicables, investiguen, y en su caso sancionen, la presunta comisión de delitos por parte de los expresidentes Carlos Salinas de Gortari, Ernesto Zedillo Ponce de León, Vicente Fox Quezada, Felipe Calderón Hinojosa y Enrique Peña Nieto antes, durante y después de sus respectivas gestiones??

En la exposición de motivos de su solicitud, señala a sus antecesores como partícipes activos y pasivos, dice él, de diversos delitos. En el numeral decimotercero precisa:

Si el pueblo da su aprobación (para que se investigue y se castigue a los expresidentes) las instituciones responsables de desahogar las potenciales acusaciones tendrán un enorme respaldo para realizar esa tarea con absoluta libertad; si rechaza la propuesta, nadie podrá acusarlas de encubrir o solapar conductas ilegales. ${ }^{10}$

La Suprema Corte, en el primero de sus proyectos, preparado por el ministro ponente Luis María Aguilar Morales, consideró a la solicitud presidencial como «un concierto de inconstitucionalidades $»^{11}$ que, por restringir los derechos humanos de presunción de inocencia, igualdad y debido proceso, además de propiciar desconfianza hacia las autoridades, se encuentra prohibida por el numeral 3 de la fracción 8 del artículo 35 de la Constitución Política de los Estados Unidos Mexicanos:

9. «Acuerdo», Suprema Corte de Justicia de la Nación (SCJN), 1/2020, Revisión de constitucionalidad de la materia de consulta popular, 1 de octubre de 2020 , foja 6, disponible en https://bit.ly/35yNsaD.

10. «Acuerdo», foja 5.

11. Proyecto del ministro ponente Luis María Aguilar Morales, no aprobado, Suprema Corte de Justicia de la Nación, 1/2020, Revisión de constitucionalidad de la materia de consulta popular, foja 43, disponible en https://bit.ly/2HtMJ29. 
No podrán ser objeto de consulta popular la restricción de los derechos humanos reconocidos por esta Constitución; los principios consagrados en el artículo 40 de la misma $[\ldots]$.

El día 1 de octubre de 2020, antes de la sesión en que la Suprema Corte discutiría y aprobaría o no el proyecto del ministro Luis María Aguilar Morales, el presidente de México y titular del Poder Ejecutivo Federal, en clara violación a los Principios Básicos de la Organización de las Naciones Unidas Relativos a la Independencia de la Judicatura, ${ }^{12}$ volvió a presionar a los ministros de la Corte. Esta vez a través de la televisión, y refiriéndose a la resolución que ese día iban a emitir sobre la consulta popular que él había solicitado, los señaló de haber pactado con «los de arriba» la inconstitucionalidad de una consulta popular previa; los acusó de asociación delictuosa y los presentó como contrarios a los intereses del pueblo, «a quien no había que tenerle miedo", expresó. ${ }^{13}$ También públicamente les advirtió que si no aprobaban su solicitud de consulta, por ser violatoria de la Constitución, entonces él haría reformar la Constitución. Las ilegítimas presiones del titular del Poder Ejecutivo sobre el Máximo Tribunal mexicano hicieron que este finalmente claudicara, que entregara su independencia ${ }^{14}$ y declarara constitucional la consulta popular. Fue su ministro presidente, Arturo Zaldívar Lelo de Larrea, quien primero se doblegó. Sorpresivamente y contra el protocolo, abrió y orientó la discusión y la votación de la Corte, declarando:

Esperaría que hoy la Corte no desaprovechara la oportunidad de asumir, con responsabilidad histórica, su rol en la protección de los derechos humanos de participación política. No nos corresponde ser una puerta cerrada, sino el puente que permita a todas las personas intervenir en las grandes discusiones nacionales, con pleno respeto a la totalidad de nuestro marco constitucional. ${ }^{15}$

12. Organización de las Naciones Unidas, Principios Básicos Relativos a la Independencia de la Judicatura: «1. La independencia de la judicatura será garantizada por el Estado y proclamada por la Constitución o la legislación del país. Todas las instituciones gubernamentales y de otra índole respetarán y acatarán la independencia de la judicatura».

13. «\#ConferenciaPresidente», canal de Youtube de Gobierno de México, 1 de octubre de 2020, disponible en https://youtu.be/50gxm452DCA; Diego Caso, «No hay que tenerle miedo al pueblo: AMLO a Suprema Corte sobre definición de consulta», El Financiero, 1 de octubre de 2020, disponible en https:// bit.ly/3J4I6qu.

14. Final previsto y reprochado por el Comité de Derechos Humanos de la Organización de las Naciones Unidas en su Observación General 32, párr. 24: «Toda situación en que las funciones y competencias del Poder Judicial y del Poder Ejecutivo no sean claramente distinguibles o en la que este último pueda controlar o dirigir al primero es incompatible con el concepto de un tribunal independiente».

15. Jessica Murillo, «SCJN declara constitucional la Consulta popular para enjuiciar a expresidentes», canal de Youtube de Noticieros Televisa, 2 de octubre de 2020, disponible en https://youtu.be/ hIegyjPuNtY. 
En ese discurso, el presidente de la Corte deja ver que su ánimo está prejuiciado, muy probablemente por las ilegítimas presiones que sobre él ha venido ejerciendo el titular del Poder Ejecutivo, prejuicio que ahora el presidente de la Corte está transmitiendo a los demás ministros. Lo anterior, en absoluta violación de la jurisprudencia de la Corte Interamericana de Derechos Humanos, que exige de los jueces carencia de todo prejuicio. ${ }^{16}$ Aunado a lo anterior, tenemos el hecho de que el ministro presidente varias veces destacó que lo que en esa ocasión resolvía la Corte no era algo jurisdiccional, sino que decidía una cuestión política, ${ }^{17}$ como queriendo justificar el hecho de que la Corte dejara de ser el Máximo Tribunal de México, para convertirse en un apéndice de los grupos políticos. ${ }^{18}$

El ministro presidente está muy equivocado. Desatiende la principalísima función jurisdiccional de la Corte en las consultas populares, que es la de emitir un juicio sobre su constitucionalidad, como expresamente se lo manda la Constitución en el artículo 35, fracción 8, apartado 3 :

La Suprema Corte de Justicia de la Nación resolverá, previo a la convocatoria que realice el Congreso de la Unión, sobre la constitucionalidad de la materia de la consulta.

Contrariando al discurso del ministro Zaldívar Lelo de Larrea, a la Corte sí le corresponde ser una puerta lo más herméticamente cerrada que sea posible, para no dejar pasar a los actos que restrinjan los derechos humanos y los principios de la república representativa, democrática, laica y federal, compuesta por estados libres y soberanos que funcionan por medio de instituciones, porque así expresamente se lo ordena la Constitución General de la República.

El ministro presidente y los ministros que lo siguieron - Yazmín Esquivel Mossa, Margarita Ríos Farjat, Alfredo Gutiérrez Ortiz Mena, Juan Luis González Alcántara Carrancá y Alberto Pérez Dayan-, en su carácter de integrantes del más Alto Tribunal, es decir, como jueces, no ignoraban lo que es evidente: que la consulta popular en cuestión restringe los derechos humanos de presunción de inocencia, igualdad y debido proceso. ¿Por qué? Porque, como expresamente lo reconoce el mismo peti-

16. «La imparcialidad exige que el juez que interviene en una contienda particular se aproxime a los hechos careciendo, de manera subjetiva, de todo prejuicio». Sentencia del caso Apitz Barbera y otros con Venezuela, Corte Interamericana de Derechos Humanos, serie C núm. 182, excepción preliminar, fondo, reparaciones y costas, 5 de agosto de 2008, párr. 56.

17. Víctor Fuentes, «Defiende Zaldívar función política de consulta popular», Reforma, 1 de octubre de 2020, disponible en https://bit.ly/37I2opt.

18. Para dejar de desempeñar las funciones jurisdiccionales que la Constitución expresamente le ha impuesto, la Suprema Corte debe antes tramitar el procedimiento de relevo, derogación, transferencia o reforma, legalmente establecido y consultable en la bien documentada y mejor argumentada investigación de Salcedo González (2013). 
cionario de la consulta, las fiscalías y los tribunales actuarán en forma distinta si el resultado de la consulta popular aprueba que se investigue y se sancione a los expresidentes de como lo harán si el resultado de la consulta es desaprobatorio. En caso de aprobación, se habrá generado en las procuradurías de justicia y en los juzgados un prejuicio de culpabilidad hacia las personas sobre quienes se consulta y respecto de quienes se ha aprobado que sean investigadas y sancionadas, además de que a dichas personas se les habrá exhibido como probables responsables sin que exista en su contra algún señalamiento, denuncia o acusación presentados ante autoridad competente, contra los que puedan defenderse, violándoseles así los derechos humanos a la presunción de inocencia, a la igualdad, al debido proceso y a la defensa adecuada, esto último en virtud de que las personas cuyos actos serán materia de la consulta popular, carecen por completo de recursos - porque estos no existen- para intervenir en el procedimiento de consulta en defensa de sus derechos. Sobre este particular, la Corte Interamericana de Derechos Humanos ha enfatizado:

El derecho a la defensa debe necesariamente poder ejercerse desde que se señala a una persona como posible autor o partícipe de un hecho punible y solo culmina cuando finaliza el proceso, incluyendo, en su caso, la etapa de ejecución de la pena. Sostener lo opuesto implicaría supeditar las garantías convencionales que protegen el derecho a la defensa, entre ellas el artículo 8.2.b, a que el investigado se encuentre en determinada fase procesal, dejando abierta la posibilidad de que con anterioridad se afecte un ámbito de sus derechos a través de actos de autoridad que desconoce o a los que no puede controlar u oponerse con eficacia, lo cual es evidentemente contrario a la Convención. ${ }^{19}$

Asimismo, sobre el ánimo de los fiscales y de los jueces que intervengan en las investigaciones y en los procedimientos aprobados en una consulta popular, siempre pesará esa aprobación, es decir, no tendrán la independencia, la neutralidad y la imparcialidad que son indispensables en las funciones fiscalizadoras y jurisdiccionales, tan es así que la Corte Interamericana de Derechos Humanos dispuso:

La independencia de cualquier juez supone que se cuente con un adecuado proceso de nombramiento, con una duración establecida en el cargo, garantías de inamovilidad y una garantía contra presiones externas. En el mismo sentido, se expresan los Principios Básicos de Naciones Unidas relativos a la Independencia de la Judicatura. $^{20}$

19. Sentencia del caso Barreto Leiva con Venezuela, Corte Interamericana de Derechos Humanos, serie C núm. 135, fondo, reparaciones y costas, 17 de noviembre de 2009, párr. 29.

20. Sentencia del caso Palamara Iribarne con Chile, Corte Interamericana de Derechos Humanos, serie C núm. 135, fondo, reparaciones y costas, 22 de noviembre de 2005, párr. 156. 
Lo anterior, aunado al hecho de que en México, como en la mayoría de los países latinoamericanos, las fiscalías son dependencias del Poder Ejecutivo, y se carece de un Poder Judicial independiente.

Es claro que la Corte, al resolver la constitucionalidad de la consulta popular, no se comportó ni podía comportarse como órgano político, sino que actuó como órgano jurisdiccional, es decir, juzgó, emitió un juicio entre dos verdades rivales, la una, asumida por el ministro ponente Luis María Aguilar Morales, compartida en lo general por los ministros Norma Lucía Piña Hernández, Jorge Mario Pardo Rebolledo, Javier Laynez Potisek y Fernando Franco González, que encontraba la consulta inconstitucional; y la otra, enarbolada por el ministro Arturo Zaldívar Lelo de Larrea, que defendía la constitucionalidad de la consulta. Ese juicio lo emitió con base en los diversos medios de prueba que tuvo a su disposición, entre los que se encontraron los consistentes en: i) la documental por la que el peticionario solicitó la consulta, ii) la confesión expresa y espontánea que produjo el peticionario de la consulta, constante en todas las intervenciones públicas en que manifestó su intención de hacer sancionar a Carlos Salinas de Gortari, Ernesto Zedillo Ponce de León, Vicente Fox Quezada, Felipe de Jesús Calderón Hinojosa y a Enrique Peña Nieto por los delitos que, según él, han cometido antes, durante y después de su respectiva gestión como presidentes de México; y iii) la presunción humana que se produjo en la mente de por lo menos ocho de los once ministros que componen la Suprema Corte de Justicia de la Nación, en el sentido de que la pregunta base de la consulta popular solicitada era tendenciosa, razón por la cual procedieron a modificarla.

Es pertinente mencionar que no solo la pregunta era tendenciosa, como lo decretaron los ocho ministros - amplia mayoría-, sino que era tendenciosa toda la solicitud de consulta. Para constatarlo basta con leer su exposición de motivos, especialmente los apartados segundo, décimo, decimosegundo, decimotercero, decimocuarto y decimoquinto, en los que el peticionario directamente señala y nombra a cinco expresidentes de México como autores y partícipes, por acción y omisión, de diversos ilícitos, por los cuales pretende que sean investigados y en su caso sancionados, intentando encubrir su interés personal con lo que él llama «masivo clamor de justicia».

Habiéndose demostrado y declarado por ocho de once ministros que la pregunta era tendenciosa, es decir, que con ella solo se pretendía satisfacer intereses particulares del peticionario, que de ninguna manera se pueden considerar tema de trascendencia nacional, era evidente que la consulta no podía ser declarada constitucional, en virtud de que lo prohibía el encabezado de la fracción 8 del artículo 35 de la Constitución: «Son derechos del ciudadano: Votar en las consultas populares sobre temas de trascendencia nacional».

La pregunta propuesta por el peticionario de la consulta, además de tendenciosa, era insidiosa, insidia con la que pretendía perjudicar al pueblo en virtud de que 
habría confundido la mente de la persona que contestara, pues le haría creer que dependía de su aprobación el que se investigaran y se sancionaran conductas delictivas, cuando los delitos de que se acusa a los expresidentes se persiguen de oficio, es decir, tanto la Fiscalía General de la República como las fiscalías estatales tienen la obligación de investigar y perseguir los actos con apariencia delictiva de que, por cualquier medio, tengan conocimiento, de ninguna manera requieren de la consulta popular ni de su resultado para cumplir - y menos aún para dejar de cumplir- las obligaciones que les imponen los párrafos primero y segundo del artículo 21 constitucional:

La investigación de los delitos corresponde al Ministerio Público y a las policías, las cuales actuarán bajo la conducción y mando de aquel en el ejercicio de esta función. El ejercicio de la acción penal ante los tribunales corresponde al Ministerio Público.

Para que no nos quede duda, el artículo 212 del Código Nacional de Procedimientos Penales ordena:

Cuando el Ministerio Público tenga conocimiento de la existencia de un hecho que la ley señale como delito, dirigirá la investigación penal, sin que pueda suspender, interrumpir o hacer cesar su curso, salvo en los casos autorizados en la misma.

Una razón más por la cual la pregunta propuesta por el peticionario era insidiosa consistía en que intentaba hacer creer a quien habría de responder, o sea, al pueblo, que si no aprobaba la investigación y la sanción contra los expresidentes, sería ella la persona que contestaba - la responsable de que los expresidentes no hubieran sido investigados y sancionados por sus supuestos actos ilícitos; incluso la haría sentir encubridora, si no es que cómplice de esos supuestos delitos. La insidia en la pregunta del peticionario de la consulta popular se evidencia al analizar lo que el peticionario expresa en el apartado décimo tercero de su exposición de motivos: «Si rechaza la propuesta, nadie podrá acusarlas de encubrir o solapar conductas ilegales». ${ }^{21} \mathrm{Em}$ bozadamente, el peticionario hace recaer en el pueblo -que es quien contesta la pregunta- la responsabilidad de encubrir y solapar las conductas ilegales que el peticionario reprocha a los expresidentes. Tras una máscara, está obligando al pueblo a aprobar su propuesta de investigar y en su caso sancionar a los expresidentes, porque de rechazarla sería responsable de encubrir y solapar sus supuestas conductas ilegales, así como de relevar a las instituciones procuradoras e impartidoras de justicia (el Ministerio Público y los jueces) de sus respectivas funciones y obligaciones públicas.

Por lo anterior, entre otras cosas, fue que la Suprema Corte modificó la pregunta propuesta por el solicitante y la dejó en los siguientes términos:

21. «Acuerdo», foja 5. 
¿Estás de acuerdo o no en que se lleven a cabo las acciones pertinentes, con apego al marco constitucional y legal, para emprender un proceso de esclarecimiento de las decisiones políticas tomadas en los años pasados por los actores políticos, encaminado a garantizar la justicia y los derechos de las posibles víctimas?22

Esta modificación no resuelve la cuestión de constitucionalidad o inconstitucionalidad de la consulta, debido a que la exposición de motivos de la solicitud se dejó intocada y es precisamente ahí, no en la pregunta, donde se encuentran los temas de trascendencia nacional y la materia de la consulta sobre los que debe pronunciarse y resolver la Suprema Corte.

La Corte, al dejar intocada la exposición de motivos de la que directamente se derivó la pregunta y modificar esta, ha generado una incongruencia entre el tema y la materia de la consulta, por un lado, y la pregunta, por el otro, incongruencia que por sí sola, de acuerdo con el artículo 21, fracción 3, y el artículo 26 de la Ley Federal de Consulta Popular, imposibilita el desarrollo y la práctica de la consulta popular solicitada. Además, como ya se habrá apreciado, la pregunta modificada por la Suprema Corte difiere mucho de la que propuso el solicitante de la consulta, por lo que en realidad podemos decir que se trata de otra consulta popular, esta vez propuesta por la Suprema Corte, pero es el caso que el artículo 35 constitucional no autoriza a la Suprema Corte a pedir consultas populares; para ello solo autoriza al Presidente de la República, al 33\% de los integrantes de cualquiera de las Cámaras del Congreso de la Unión y al 2\% de los ciudadanos inscritos en la lista nominal de electores.

La consulta popular se llevó a cabo el 1 de agosto de 2021. Resultó un fracaso, no acudió a votar el porcentaje de la población que la ley exige para que el resultado sea vinculatorio. El titular del Poder Ejecutivo Federal ya culpó del fracaso de su consulta al Instituto Nacional Electoral (INE), a quien señala de haber desalentado al electorado. La Cámara de Diputados, cuya mayoría pertenece al partido político del titular del Ejecutivo Federal, ya citó a comparecer a Lorenzo Córdova Vianello, presidente del INE, a fin de cuestionarle su presupuesto para 2022, entre otras cosas. La consulta costó al pueblo de México MXN 500 millones (cerca de USD 23 millones), es decir, más que los MXN 471 millones por los que la Fiscalía General de la República, dependencia del Poder Ejecutivo Federal, persigue, acosa y acusa a 31 científicos del Consejo Nacional de Ciencia y Tecnología, contra quienes, en dos ocasiones, ha solicitado órdenes de aprehensión porque, según la Fiscalía, no ejercieron su presupuesto con austeridad republicana, mientras que la consulta popular solicitada por el titular del Ejecutivo Federal «tiró a la basura» más dinero del que gastaron los miembros del Consejo Nacional de Ciencia y Tecnología, a quienes se les acusa de delincuencia organizada.

22. «Acuerdo», foja 34. 
El presidente del INE puede ser investigado y acusado de haber ejercido «cualquier tipo de presión sobre el electorado» para que se abstuviera de votar durante el procedimiento de la consulta popular, puede ser detenido cuando se presente a su cita en la Cámara de Diputados, y ser sujeto a prisión preventiva oficiosa. En el mejor de los casos, recuperaría su libertad en dos años, habiendo dejado de ser un estorbo, durante ese plazo, para los planes de consolidación del actual partido político mayoritariamente gobernante. Todo lo anterior, gracias a las reformas implantadas por el Congreso de la Unión, a través de su Decreto de 18 de febrero de 2021.

\section{Otros hechos relacionados con la prisión preventiva oficiosa}

El Ejército Zapatista de Liberación Nacional (EZLN) es una organización de insurgencia armada que opera en el sureste del territorio mexicano, defendiendo los intereses de los pueblos originarios de esa región. En septiembre de 2021, advirtió que pronto van a ocurrir acontecimientos de suma importancia en la zona. Es probable que se refiera a la defensa que van a ejercer los pueblos indígenas en contra de la construcción de la vía general de comunicación, conocida como Tren Maya, que está siendo construida por el Ejército mexicano, bajo las órdenes del titular del Ejecutivo Federal, y proyecta atravesar los territorios de influencia zapatista, sin que se haya presentado la consulta previa e idónea que ordena el Convenio 169 de la Organización Internacional del Trabajo. El derecho a protestar que - en defensa de sus tierras, bosques, aguas, rutas y tradiciones ancestrales - van a expresar los pueblos originarios, de seguro interrumpirá la construcción de la vía general de comunicación en cuestión y provocará la represión del gobierno con una de sus mejores armas: el derecho penal, particularmente con la prisión preventiva oficiosa, para poner fuera de circulación a los insurrectos, contra quienes se mandará a la recién creada Guardia Nacional, a la Marina y al Ejército, letales cuerpos de seguridad que el gobierno federal mexicano está adiestrando en el uso de equipo táctico, recientemente adquirido, para señalar, perseguir y capturar a quienes pública y organizadamente manifiesten sus ideas contrarias al régimen. Al efecto, el actual presidente de México, en la tercera parte de su mandato (dos años), había asignado al Ejército fondos 500\% más cuantiosos que los que le asignó Felipe Calderón Hinojosa en todo el ejercicio de su gobierno (seis años). ${ }^{23}$

Con el ataque sistemático que se ha desatado desde las cúpulas del gobierno federal mexicano en contra de las universidades y otros centros de enseñanza superior, los medios de comunicación independientes, la gente de ciencia, los artistas, las mujeres, los actores políticos no afines, las víctimas de desastres naturales y de

23. Elena Reina, «López Obrador aumenta el poder del Ejército con un incremento histórico de fondos en cuatro fideicomisos», El País, 14 de octubre de 2020, disponible en https://bit.ly/3260mO7. 
violaciones a derechos humanos, los enfermos —entre estos, los niños con cáncer-, así como contra cualquier persona que se atreva a criticar las acciones y las omisiones gubernamentales, es claro que en el México de 2021 no hay lugar para la oposición, y para quienes no lo entiendan, se cuenta con la prisión preventiva oficiosa.

\section{La prisión preventiva oficiosa y la América Latina: El caso de Chile}

La prisión preventiva oficiosa es un flagelo en México y amenaza con extenderse a otros países de América Latina, ${ }^{24}$ propiciando el regreso del autoritarismo. Por ejemplo, en Chile podría implementarse, en virtud de que ahí, entre los años 2000 y 2010, bajo el sistema procesal penal acusatorio, creció el temor a la inseguridad, fenómeno que llevó a parte de la sociedad a exigir a su gobierno soluciones prontas. Los legisladores andinos respondieron con el aumento de la prisión preventiva justificada, al efecto exigieron mayores - y a veces inalcanzables- requisitos para la concesión de la libertad provisional garantizada durante la tramitación del procedimiento penal. Por su parte, los fiscales aumentaron sus solicitudes de encarcelamiento preventivo, que cada vez con mayor facilidad han concedido los órganos jurisdiccionales (Duce y Riego, 2011: 159-161). Compartimos las preocupaciones del estudioso chileno Marcelo Hadwa Issa, quien considera que su país se encamina hacia la prisión preventiva automática, toda vez, dice, que fueron rebajadas las barreras que limitaban la procedencia de la prisión preventiva justificada, «en un claro y peligroso avance hacia la automatización de su adopción» (Hadwa, 2015: 20). Agrega: «Este fenómeno no es exclusivo de Chile, muchos otros países latinoamericanos que optaron por el establecimiento de sistemas procesales penales más liberales y por la modificación de la matriz que regula la prisión preventiva también han ido sucumbiendo a la tentación de flexibilizar los criterios de aplicación de esta medida» (Hadwa, 2015: 20).

Los doctrinarios, así como las organizaciones defensoras de los derechos humanos en Chile, consideran que se están violando los derechos fundamentales de las personas procesadas y que no se están respetando las convenciones internacionales de las que ese país forma parte, muy particularmente en cuanto a la excepcionalidad de la prisión preventiva, la progresividad de los derechos humanos, la proporcionalidad entre la falta y la sanción, así como con la jurisprudencia integrada con las resoluciones de la Corte Interamericana de Derechos Humanos, cuestiones sobre las

24. «Informe sobre medidas dirigidas a reducir el uso de la prisión preventiva en las Américas», Comisión Interamericana de Derechos Humanos, julio de 2017: «Desde hace dos décadas, la CIDH ha señalado que la aplicación arbitraria e ilegal de la prisión preventiva es un problema crónico en la región» (p. 11). «El uso no excepcional de la prisión preventiva continúa constituyendo uno de los problemas más graves y extendidos que enfrentan los Estados de la OEA en cuanto al respeto y garantía de los derechos de las personas privadas de libertad» (p. 153). Véase también «Global prison trends», Penal Reform International y Thailand Institute of Justice, 2020, disponible en https://bit.ly/2HBw2Sk. 
que Claudio Nash Rojas y Constanza Núñez Donald advierten que, al ser la libertad personal uno de los pilares sobre los cuales se construye la idea de la dignidad humana, cualquier afectación o menoscabo que le cause el Estado debe estar sujeto a condiciones estrictas (Nash y Núñez, 2016: 113-115) que son esbozadas por la Corte Interamericana de Derechos Humanos:

El artículo 7 de la Convención consagra garantías que representan límites al ejercicio de la autoridad por parte de agentes del Estado. Esos límites se aplican a los instrumentos de control estatales, uno de los cuales es la detención. Dicha medida debe estar en concordancia con las garantías reconocidas en la Convención, siempre y cuando su aplicación tenga un carácter excepcional y respete el principio a la presunción de inocencia y los principios de legalidad, necesidad y proporcionalidad, indispensables en una sociedad democrática. ${ }^{25}$

Según esta jurisprudencia, una sociedad antidemocrática, autoritaria, dictatorial, es aquella que no respeta los principios de presunción de inocencia, legalidad, necesidad y proporcionalidad. La prisión preventiva oficiosa, bastión de la política criminal mexicana (Salcedo, 2016: 605-609), quebranta todos y cada uno de esos principios. Al bastar un mero señalamiento para perder la libertad, es claro que no se respeta la presunción de inocencia. Al contrariarse la Declaración Universal de los Derechos Humanos, en su artículo 9; el Pacto Internacional de Derechos Civiles y Políticos, en su artículo 9.1; y la Convención Americana sobre Derechos Humanos en sus artículos 8.1 y 8.2, se evidencia la violación del principio de libertad. Al prohibirse al juez motivar la necesidad y la proporcionalidad de la prisión preventiva, es cierto que se incumplen los principios de la democracia, y la privación de la libertad se torna arbitraria a la luz de la jurisprudencia de la Corte Interamericana de Derechos Humanos: «Cualquier restricción a la libertad que no contenga una motivación suficiente que permita evaluar si se ajusta a las condiciones señaladas será arbitraria y, por tanto, violará el artículo 7.3 de la Convención»». ${ }^{26}$

Si al juez se le prohíbe analizar los hechos, las pruebas, las normas jurídicas, para determinar si existen o no indicios suficientes que permitan suponer razonablemente que la persona procesada participó en el ilícito que se investiga; si al juez se le impide verificar, con base en circunstancias objetivas y ciertas del caso concreto, que la libertad del imputado pone en peligro el procedimiento; y se le impone, desde la letra de la ley, la obligación de decretar la prisión preventiva en todos los casos particularmente

25. Sentencia del caso Familia Barrios con Venezuela, Corte Interamericana de Derechos Humanos, serie C núm. 237, fondo, reparaciones y costas, 24 de noviembre de 2011, párr. 53.

26. Caso Mujeres Víctimas de Tortura Sexual en Atenco con México, Corte Interamericana de Derechos Humanos, serie C núm. 371, excepción preliminar, fondo, reparaciones y costas, 28 de noviembre de 2018, párr. 250. 
catalogados por el grupo en el poder, es claro que al juez se le despoja no solo de su independencia y autonomía, sino de su jurisdicción toda, también en flagrante violación a la jurisprudencia emitida por la Corte Interamericana de Derechos Humanos:

Concordantemente, las características personales del supuesto autor y la gravedad del delito que se le imputa no son, por sí mismos, justificación suficiente de la prisión preventiva. El peligro procesal no se presume, sino que debe realizarse la verificación del mismo en cada caso, fundado en circunstancias objetivas y ciertas del caso concreto. ${ }^{27}$

\section{La democracia y la prisión preventiva oficiosa}

Hemos visto que la prisión preventiva oficiosa atenta en contra de cuatro de los derechos humanos pilares, que son la libertad personal, la presunción de inocencia, el acceso a la justicia y el debido proceso.

Constatamos que la prisión preventiva oficiosa viola el derecho al sufragio universal, ya que impide al elector informarse adecuadamente, debatir y votar libremente, pues su decisión, según la ley, no puede ser influenciada por elemento alguno, menos aún por aquellos que cuestionan la eficacia de los programas sociales.

Corroboramos que la prisión preventiva oficiosa impide al juez ejercer su jurisdicción, ya que es desplazado por el legislador, que es quien en realidad decreta la prisión de la persona señalada de haber cometido el ilícito.

Tenemos entonces, que el actual gobierno mexicano es un enemigo de la democracia, al haber establecido la prisión preventiva oficiosa para 71 delitos, cuando antes de su llegada en 2018 era solo para 6 . Hoy se aplica a un total de 77 delitos, y la lista crece desmesuradamente.

La Corte Interamericana de Derechos Humanos considera a la prisión preventiva oficiosa un mal para la democracia:

[En] una sociedad democrática los derechos y libertades inherentes a la persona, sus garantías y el Estado de derecho constituyen una tríada, en la que cada componente se define, completa y adquiere sentido en función de los otros. ${ }^{28}$

$\mathrm{Si}$, como vimos, la prisión preventiva oficiosa atenta en contra de los derechos y libertades inherentes de la persona, así como en contra de sus garantías, en consecuencia, no hay Estado de Derecho y menos aún democracia, lo cual nos conduce a la dictadura.

27. Sentencia del caso J. con Perú, Corte Interamericana de Derechos Humanos, serie C núm. 275, excepción preliminar, fondo, reparaciones y costas, 27 de noviembre de 2013, párr. 159.

28. Sentencia del caso Yatama con Nicaragua, Corte Interamericana de Derechos Humanos, serie C núm. 191, excepciones preliminares, fondo, reparaciones y costas, 23 de junio de 2005, párr. 191. 


\section{Conclusiones}

La prisión preventiva oficiosa es un instrumento que aniquila a la democracia y favorece a la dictadura, entendida esta como el régimen político en el que una sola persona gobierna con poder absoluto, sin someterse a ningún tipo de limitaciones y con la facultad de promulgar y reformar leyes a su conveniencia. En el presente trabajo, hemos visto cómo el actual titular del Poder Ejecutivo Federal mexicano utiliza a la prisión preventiva oficiosa para privar y restringir los derechos humanos, para perpetuarse en el poder e impedir que otros compitan y accedan a su ejercicio, así como para eliminar al Poder Judicial y neutralizar al Poder Legislativo. Actitudes que violan flagrantemente todos y cada uno de los elementos esenciales de la democracia, consagrados sintéticamente en el artículo 3 de la Carta Democrática Interamericana de la Organización de los Estados Americanos:

Son elementos esenciales de la democracia representativa, entre otros, el respeto a los derechos humanos y las libertades fundamentales; el acceso al poder y su ejercicio con sujeción al estado de derecho; la celebración de elecciones periódicas, libres, justas y basadas en el sufragio universal y secreto como expresión de la soberanía del pueblo; el régimen plural de partidos y organizaciones políticas, y la separación e independencia de los poderes públicos.

Carta Democrática de la que México, aún, forma parte.

\section{Referencias}

DucE, Mauricio y Cristián Riego (2011). La prisión preventiva en Chile: Análisis de los cambios legales y su impacto. Santiago: Ediciones UDP.

HADwA, Marcelo (2015). La prisión preventiva y otras medidas cautelares personales. Santiago: Jurídica de Chile.

LLOBET RODRÍGUEZ, Javier (2009). «La prisión preventica y la presunción de Inocencia según los órganos de protección de los derechos humanos del Sistema interamericano». Ius, 3 (24): 114-148. DOI: 10.35487/rius.v3i24.2009.202.

NAsh, Claudio y Constanza Núñez (2016). Derechos humanos y proceso penal: Estándares de la jurisprudencia interamericana. Ciudad de México: Instituto Interamericano de Derechos Humanos, Ubijus y Centro de Estudios de Actualización en Derecho.

SALCEDO, Antonio (2016). «El sistema procesal penal acusatorio mexicano: Formalidades y realidades», Alegatos, 94: 603-624. Disponible en https://bit.ly/3oqs2VU.

-. (2018a). «La prisión preventiva, ¿condena anticipada?» Alegatos, 98: 33-56. Disponible en https://bit.ly/37CpVs9.

-. (2018b). «¿México cumple los estándares internacionales sobre prisión preventiva?». Alegatos, 99: 237-250. Disponible en https://bit.ly/3dU61dh. 
-. (2019). «La prisión preventiva oficiosa es un crimen de lesa humanidad». Alegatos, 102-103: 239-264. Disponible en https://bit.ly/34p6voy.

Salcedo González, Sandra (2013). «Reforma constitucional de derechos humanos: La facultad de investigación de la SCJN a la CNDH». En José Antonio Ibáñez Aguirre y Sandra Salcedo González (coordinadores), Ombudsman: Asignatura pendiente en México (pp. 121-181). Ciudad de México: Universidad Iberoamericana.

\section{Sobre el autor}

Antonio Salcedo Flores es licenciado en Derecho por la Universidad Autónoma Metropolitana, México. Especialista, maestro y doctor en Derecho por la Universidad Panamericana, México. Ex juez familiar del Tribunal Superior de Justicia del Distrito Federal. Profesor Investigador de la Universidad Autónoma Metropolitana desde 1981, donde se desempeña como docente de Derecho Procesal y miembro del Núcleo Básico del Área de Investigación Derechos Humanos y Alternatividad Jurídico Social; y fue jefe del Departamento de Derecho, así como fundador y coordinador del Bufete Jurídico. Su correo electrónico es asf@azc.uam.mx. (D) https://orcid. org/0000-0002-1285-9344. 